International Journal of Osteoarchaeology

Int. J. Osteoarchaeol. 17: 451-464 (2007)

Published online 21 February 2007 in Wiley InterScience

(www.interscience.wiley.com) DOI: 10.1002/oa.890

\title{
Scapular Development from the Neonatal Period to Skeletal Maturity: A Preliminary Study
}

\author{
C. RISSECH ${ }^{\mathrm{a}, \boldsymbol{b} *}$ AND S. BLACK ${ }^{\mathbf{c}}$ \\ a Departamento de Antropologia, Universidade de Coimbra, Portugal \\ b Unitat d'Antropologia Biologica, Universitat Autònoma de Barcelona, Spain \\ ${ }^{c}$ Anatomy and Forensic Anthropology, University of Dundee, UK
}

\begin{abstract}
An understanding of the basic growth rates and patterns of development for each element of the human skeleton is important for a thorough understanding and interpretation of data in all areas of skeletal research. Yet surprisingly little is known about the detailed ontogenetic development of many bones, including the scapula. With the intention of describing the changes that accompany postnatal ontogeny in the scapula and algorithms to predict subadult age at death, this communication examines the development of the scapula through nine measurements ( 3 from the glenoidal area, 4 from the body and 2 related to the spinous process) by polynomial regression. Data were collected from 31 of the individuals that comprise the Scheuer Collection, which is housed at the University of Dundee (Scotland).

Four of the derived mathematical curves (scapular length, infra- and suprascapular height and spine length) displayed linear growth, whilst three (maximum length of the glenoid mass, acromial width and scapular width) were best expressed by a second-degree polynomial and two (maximum and middle diameter of the glenoidal surface) by a third-degree polynomial. All single measurements proved useful in the prediction of age at death, although derived indices proved to be of limited value. In particular, scapular width, suprascapular height and acromial width showed reliable levels of age prediction until late adolescent years. Copyright (c) 2007 John Wiley \& Sons, Ltd.
\end{abstract}

Key words: scapular growth; immature bones; age prediction

\section{Introduction}

Growth studies are central to the accurate reconstruction of demographic profiles for past populations, and the reliable evaluation of age at death is core to the assessment and interpretation of many factors including indicators of health status and life conditions. It therefore follows that the normal pattern and progression of growth and skeletal maturation must be understood for each

\footnotetext{
* Correspondence to: Unitat Antropologia, Dept. Antropologia Animal, Vegetal i Ecologia, Facultat de Ciències, Universitat Autònoma de Barcelona, 08193, Bellaterra, Spain.

e-mail: carme.rissech@uab.es
}

skeletal element to permit a realistic evaluation of the discriminatory potential for any bone that might present in an assemblage. It is also important that the methodology be based on osteological material of documented biological identity (i.e. known sex, age and ethnic origin) to avoid inappropriate circular arguments relating to the establishment of methods derived from a dependent and inherent pre-existing age profile (Bocquet-Appel \& Masset, 1985; Black \& Scheuer, 1996; Rissech et al., 2003).

Recent literature has highlighted the lack of primary information regarding the developing human skeleton, and this has resulted in a poor understanding of growth patterns in different 
regions of the skeleton (Scheuer \& Black, 2000). Current work on the innominate (Major, 2000; Rissech et al., 2003; Rissech \& Malgosa, 2005) and the femur (Rissech, 2003) has begun to redress this situation, but the limitation often lies with the lack of documented material upon which to base an osteological growth study of this nature.

Despite extensive literature on the scapula (Graves, 1921, 1922; Gray, 1942; Hrdlicka, 1942a,b; Vallois, 1946; Khoo \& Kuo, 1948; Wolffson, 1950; Bainbridge \& Tarazaga, 1956; Olivier \& Pineau, 1957; McKern \& Stewart, 1957; Hanihara, 1959; Iordanidis, 1961; Fazekas \& Kósa, 1978; Schulter-Ellis, 1980; Shulin \& Fangwu, 1983; Saunders et al., 1993; Miles \& Bulman, 1995), there is a paucity of information relating to its pre- and postnatal growth profile (Hrdlicka, 1942a; Vallois, 1946; Fazekas \& Kósa, 1978; Saunders et al., 1993; Miles \& Bulman, 1995). In addition, only a small proportion of these studies have utilised documented skeletal collections (Hrdlicka, 1942a; Vallois, 1946; Fazekas \& Kósa, 1978), and all have focused on the earliest growth period where skeletal material is more abundant. This leads to a limitation on the ability to establish reliable algorithms for age prediction when so little is known about the largest portion of the postnatal growth spectrum.

From this perspective, this paper examines cross-sectional information on the growth of the scapula from documented skeletal material through the full developmental spectrum from birth to the attainment of adult form. The main purpose of this study is to analyse the growth of the scapula, with the intention of describing the changes that accompany postnatal ontogeny in this bone and develop algorithms that facilitate accurate evaluation of sub-adult age at death.

\section{Material and methods}

Scapulae were selected from the Scheuer Collection of juvenile skeletal remains which is housed in Anatomy and Forensic Anthropology at the University of Dundee (UK). This collection arose from the accumulation of forensic, anatomical and archaeological sub-adult skeletons that formed the basis of two textbooks (Scheuer \&
Black, 2000, 2004). Most of the individuals in the Scheuer Collection have documented biological identity (age and sex known). For the remainder, which are archaeological specimens, sex and age were estimated by several methods (Crétot, 1978; Weaver, 1979; Brothwell, 1981; Krogman \& Iscan, 1986; Schutkowski, 1987, 1993; Alduc-Le Bagouse, 1988; Ubelaker, 1989; Black \& Scheuer, 1996; Rissech \& Malgosa, 1997, 2005; Rissech et al., 2003; Kahana et al., 2003 among others).

Following exclusion of fragmentary specimens or those that displayed abnormal conditions, 31 individuals ( 8 males, 13 females and 10 of undocumented sex) were selected that ranged from neonatal to 19 years of age. Where possible, both right and left sides were measured. This resulted in a final sample size of 55 scapulae aged between birth and 19 years. Table 1 shows details of the distribution of age and sex in this sample.

Classical scapular metrics were recorded (length and width of the scapula, infra- and supra-scapular heights, spine length and maximum and middle diameter of the glenoid articular surface). Two new measurements relating to the glenoid mass and the acromion were included. All measurements were recorded to the nearest $0.1 \mathrm{~mm}$ using sliding callipers.

Definitions of these measurements are as follows:

(1) Maximum length of the glenoidal surface (Figures 1a and 2b): distance between the superior and inferior borders of the glenoid articular surface (Hrdlicka, 1942a; Olivier, 1960).

(2) Middle diameter of the glenoidal surface (Figures $1 \mathrm{a}$ and $2 \mathrm{~b}$ ): distance from the middle of the posterior border of the glenoidal rim to

Table 1. Specimens used in the study per group of age and sex

\begin{tabular}{lcccr}
\hline Age & Sex not known & Males & Females & $n$ \\
\hline 0-4 years & 11 & 2 & 6 & 19 \\
5-8 years & 5 & 2 & 2 & 9 \\
9-12 years & 2 & 2 & 6 & 10 \\
13-16 years & - & 2 & 3 & 5 \\
17-19 years & - & 6 & 6 & 12 \\
Total & 18 & 14 & 23 & 55 \\
\hline
\end{tabular}

Int. J. Osteoarchaeol. 17: 451-464 (2007)

DOI: $10.1002 /$ oa 


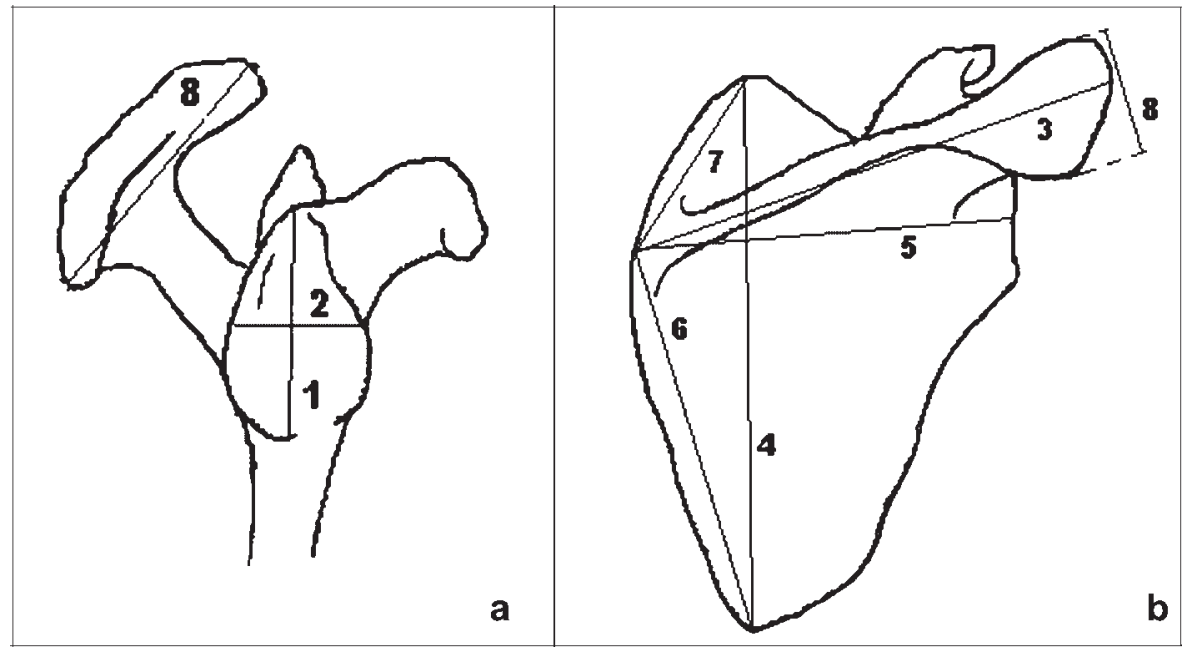

Figure 1. Lateral (a) and dorsal (b) view of adult scapula. Maximum length (1) and middle diameter (2) of the glenoidal surface; scapular spine length (3); scapular length (4); scapular width (5); infra-scapular height (6); supra-scapular height (7); and acromial width (8).

the anterior border perpendicular to the maximum length (Hrdlicka, 1942a).

(3) Maximum length of the glenoidal mass (Figures $2 \mathrm{~b}, 3$ and 4 ): distance between the superior border of the articulation site for the coracoid process and the inferior border of glenoid surface. If the coracoid is fused, the distance from the intersection point between the coracoid tubercle and the surgical neck, and the inferior border of the glenoid surface will be taken.

(4) Scapular spine length (Figures $1 \mathrm{~b}$ and $2 \mathrm{a}$ ): maximum distance between the medial end of the spine and the tip of the acromion process (Vallois, 1946; Fazekas \& Kósa, 1978).

(5) Scapular length (Figures $1 \mathrm{~b}$ and $2 \mathrm{a}, \mathrm{b})$ : maximum distance between superior and inferior

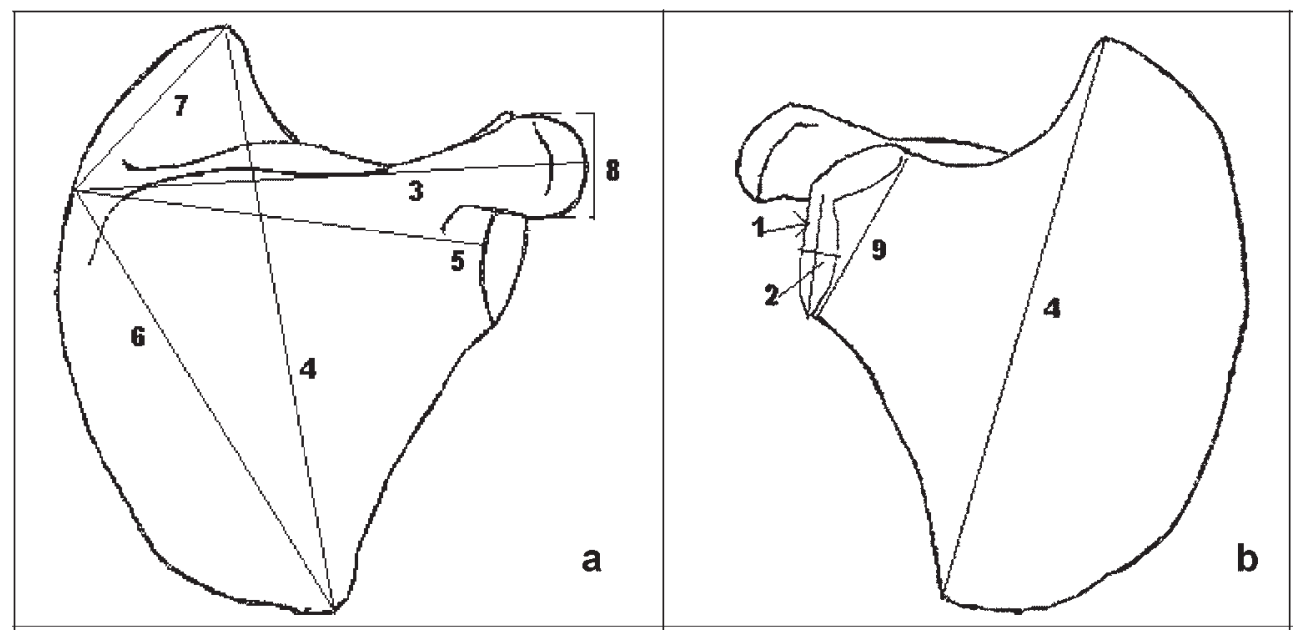

Figure 2. Dorsal (a) and ventral (b) view of sub-adult scapula. Maximum length (1) and middle diameter (2) of the glenoidal surface; scapular spine length (3); scapular length (4); scapular width (5); infra-scapular height (6); suprascapular height (7); acromial width (8); and maximum length of the glenoidal mass (9). This last measurement includes the glenoidal surface and the coracoid process. 


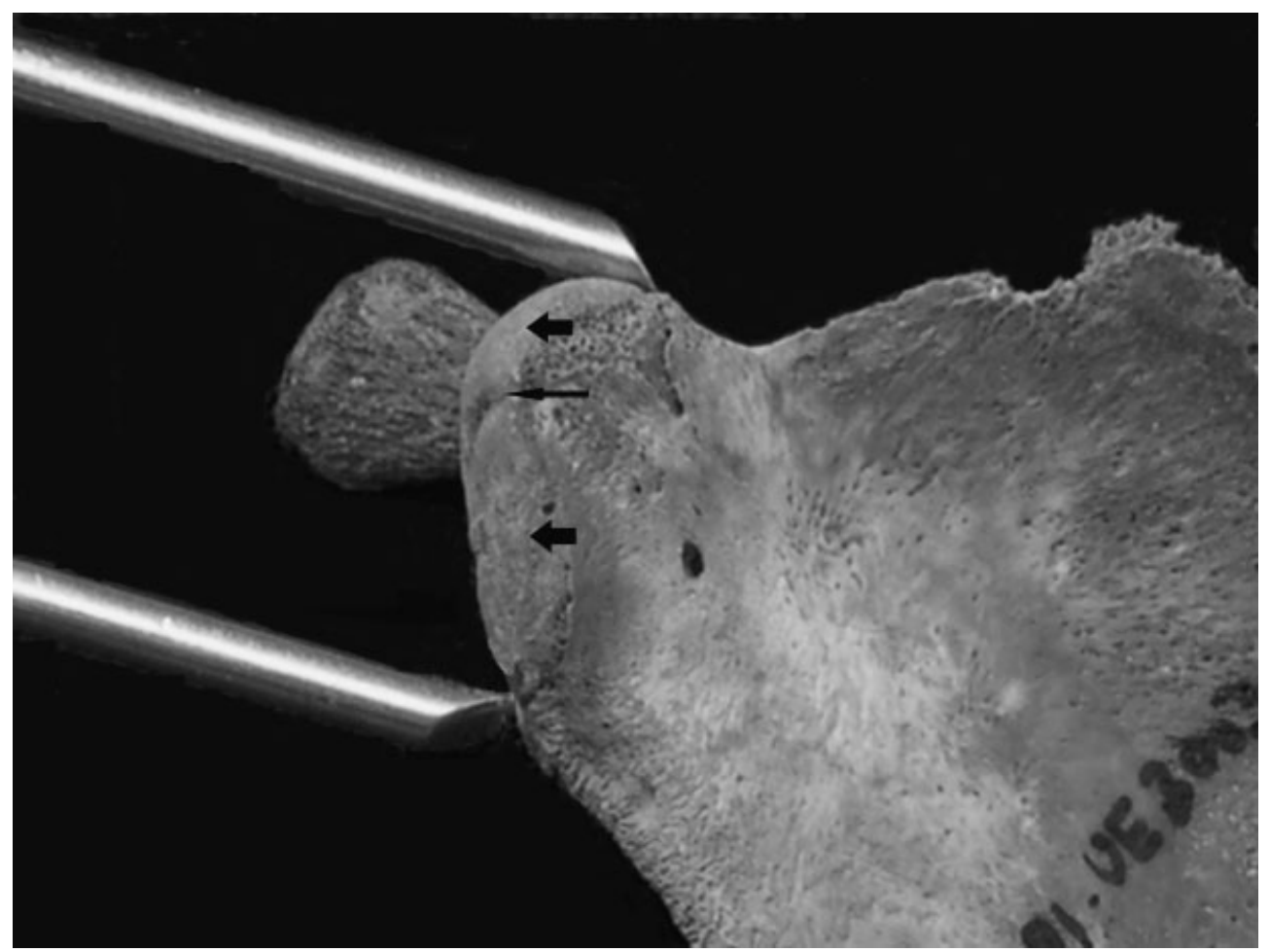

Figure 3. Ventral view of a sub-adult right scapula from a female of 41 weeks of intrauterine life. The extremes of the calliper show the maximum length of the glenoidal mass. The thin arrow shows the line of separation between coracoid site (superior wide arrow) and the glenoid fossa (inferior wide arrow).

scapular angles (Broca, 1878; Fazekas \& Kósa 1978).

(6) Scapular width (Figures $1 \mathrm{~b}$ and $2 \mathrm{a}$ ): distance between the posterior border of the glenoid rim and the medial end of the spine (Broca, 1878; Fazekas \& Kósa, 1978).

(7) Infra-scapular height (Figures $1 \mathrm{~b}$ and $2 \mathrm{a}$ ): distance between the point at which the axis of the spine intersects the medial border of the scapula to the inferior angle (Hrdlicka, 1942a $a_{i}$ Pospísil, 1965).

(8) Supra-scapular height (Figures $1 \mathrm{~b}$ and 2a): distance between the point at which the axis of the spine intersects the medial border of the scapula to the superior angle (Broca, 1878; Pospísil, 1965).

(9) Acromial width (Figure $1 \mathrm{a}, \mathrm{b}$ and Figure 2a): maximum width between the anterior and posterior borders of the acromion process, perpendicular to the axis of the scapular spine.

Copyright (C) 2007 John Wiley \& Sons, Ltd.
(10) Scapular index: percentage ratio between scapular width (6) and the scapular length (5) (Broca, 1878).

(11) Glenoidal index: percentage ratio between the middle diameter (2) and maximum diameter (1) of the glenoidal surface (total glenoid cavity index of Hrdlicka, 1942a).

(12) Supra-infra scapular index: percentage ratio between supra-scapular (8) and infra-scapular (7) heights (Broca, 1878).

\section{Statistical analysis}

Preliminary comparisons (Mann-Whitney U-test and Graphic Lowes method) showed: (a) negligible differences between right and left bones allowing for combination of them; and (b) similar patterns of growth and no significant differences in the means of the variables between 


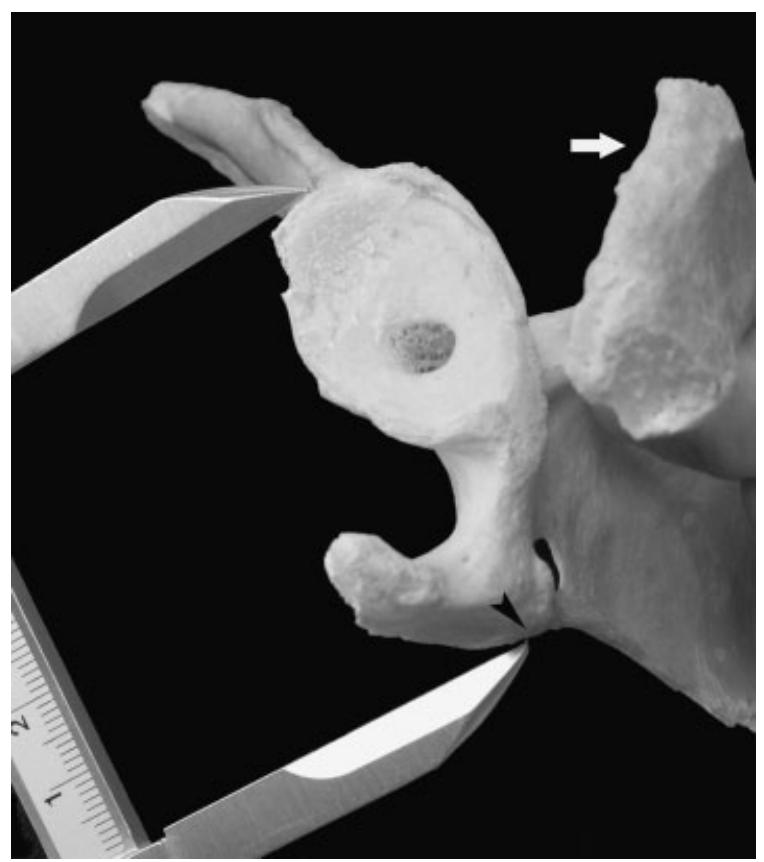

Figure 4. Lateral view of adult male scapula. The extremes of the calliper show the maximum length of the glenoidal mass when coracoid process is fused. Arrowhead indicates the intersection point between the coracoid tubercle and the surgical neck of the scapula. Arrow indicates the acromion.

the two sexes in each age group until age 16, allowing combination of the sexes in the younger age ranges.

To have a first approximation of growth before and after sexual dimorphism, the means and standard deviations for each scapular variable in each age group (4-year intervals) were calculated. However, results should be used carefully due to the small size of the sample. Moreover, it should be taken into account that the rhythm of growth is not the same within and among groups. Therefore, our reason for using this calculus is only to have an image of the growth and dimorphism at different stages of life.

To analyse the growth of the scapula before the development of sexual dimorphism, polynomial regression models were performed for each variable taking into account all the individuals under the age of the development of appreciable sexual dimorphism in that variable. In general terms, growth may be described by the lowest order polynomial (Tanner, 1962; Coleman, 1969; Strádalová, 1978). The best statistical model was selected on the basis of three factors: (1) the strength of the correlation coefficient $\left(\mathrm{R}^{2}\right)$; (2) the significance of the function expressed by the $\mathrm{F}$ value; and (3) the significance of the coefficients of the function obtained by the ANOVA test.

To predict age at death from the variables, their inverse relationship was calculated by using age as the dependent variable. Polynomial regressions were calculated using Windows SPSS (v. 12.0).

\section{Results}

Table 2 shows the mean and the standard deviation of the variables in the age groups. Between birth and 16 years the sexes were combined. For the sake of clarity, the variables are listed by topographical positioning.

\section{Glenoidal region}

The variables included maximum length and middle diameter of the glenoidal surface, maximum length of the glenoidal mass, and glenoidal index. All variables displayed an increase up to 19 years of age (Table 2) with the exception of glenoidal index, which decreased slightly until 16 years. After this age, the index increased, suggesting that maximum diameter grows slightly faster than middle diameter during the first 16 years of life, and after this age it is the middle diameter that predominates.

Between 17 and 19 years of age (Table 2), male values significantly exceeded female values for all variables pertaining to the glenoidal region with the exception of glenoidal index, in which sexual dimorphism did not reach statistical significance. These results agree in principle with the findings of Dorsey (1897), Dwight (1887), Corrêa (1915), Vallois (1946) and Hrdlicka (1942a). However, Vallois and Correa identified significant sexual dimorphism for glenoidal index. This disagreement may be explained by a slightly different definition for measuring the width of the glenoidal surface between the two studies. 


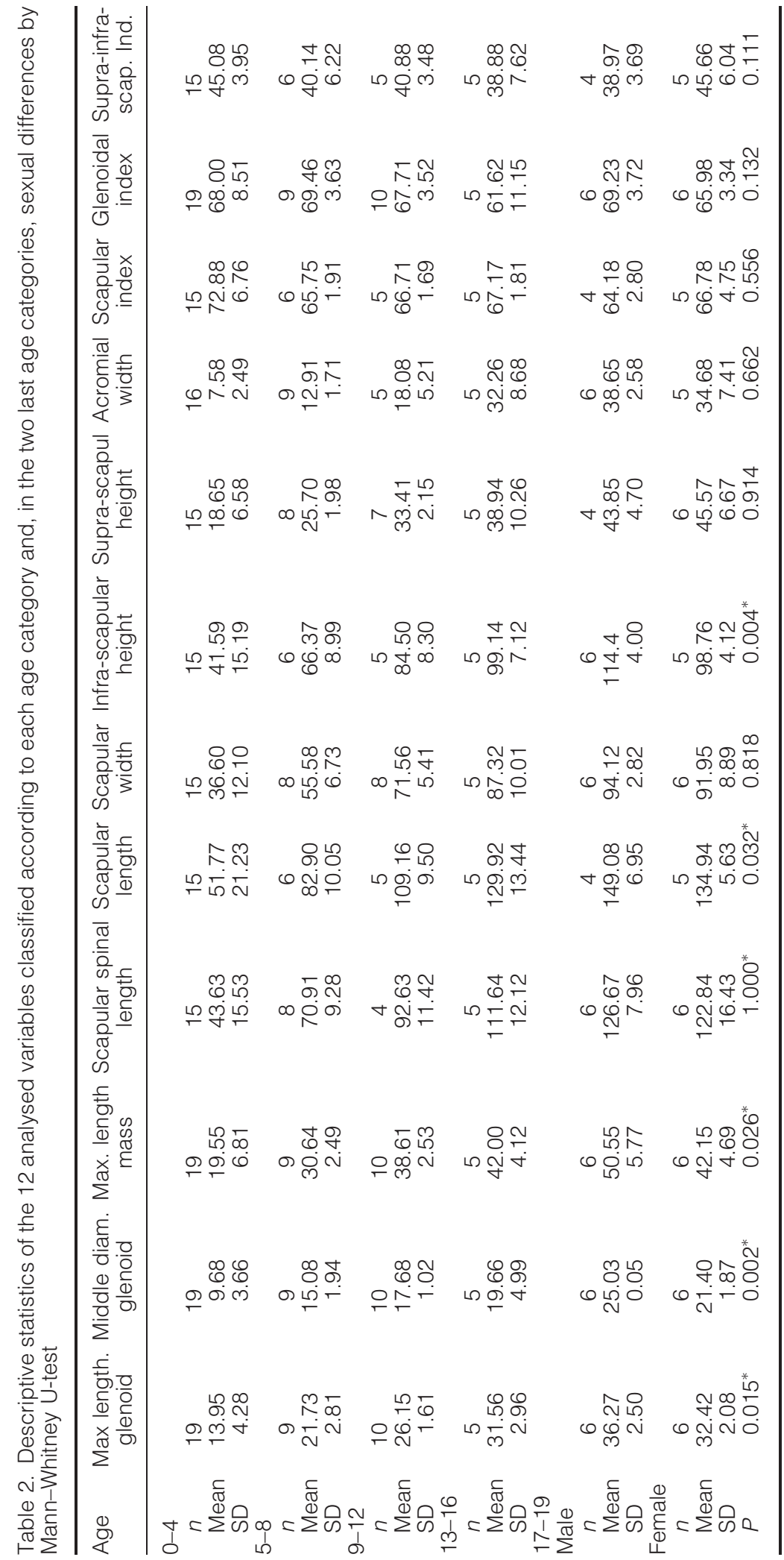




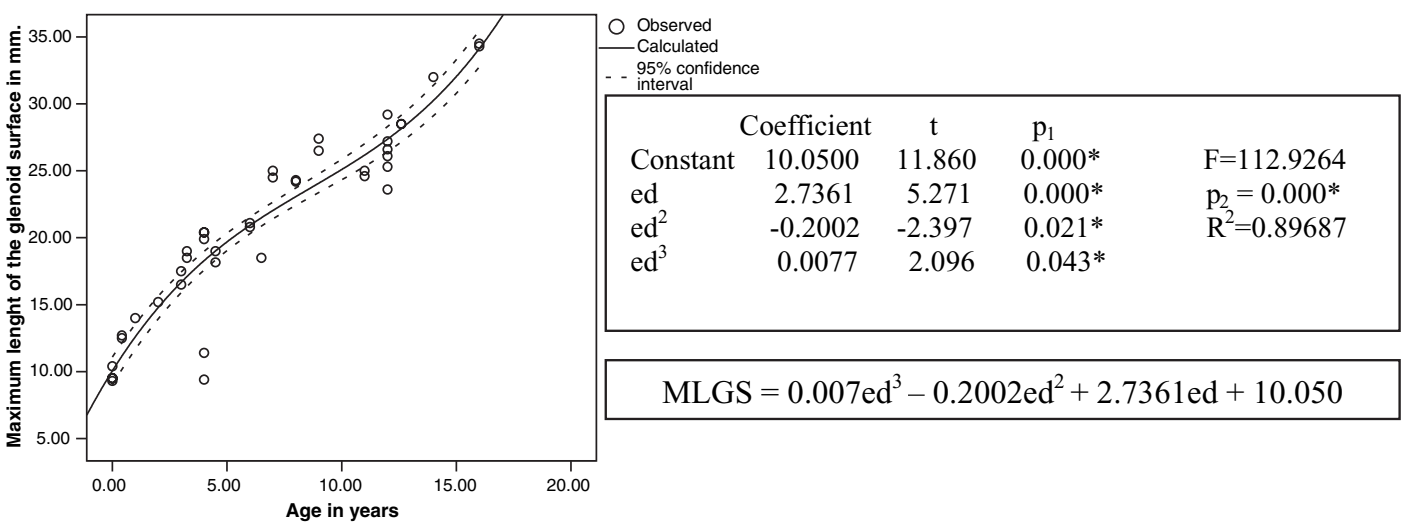

Figure 5. Polynomial regression line with 95\% confidence intervals and equation for maximum length of the glenoid surface (MLGS). Coefficient=coefficients of the function; ed=age; $t$ and $p_{1}$ the statistical significance of the coefficients; $\mathrm{F}$ and $\mathrm{p}_{2}$ the significance of the function; and $\mathrm{R}^{2}$ the explained variability.

The best growth model for maximum length and middle diameter of the glenoidal surface (Figures 5 and 6) was a third-degree polynomial regression with an explained variability of $90 \%$ and $81 \%$ respectively. For maximum length of the glenoidal mass (Figure 7) the best model was a second-degree polynomial regression with an explained variability of $89 \%$.

Glenoidal index displayed considerable variability. The best growth model for this variable was a first-degree polynomial regression with an explained variability of only $1 \%$. Dispersion is normal in indices as they reflect a multiplicity of factors (Genoves, 1959; Rissech et al., 2003; Rissech \& Malgosa, 2005). Due to the variability and dispersion involved, its value as a predictor of age was not considered.

Maximum length and middle diameter of the glenoidal cavity and maximum length of the glenoidal mass were found to be useful predictors of age up to 16 years, prior to the onset of sexual dimorphism. Therefore the inverse relationships between these variables and age were calculated. The results for these analyses (Table 3 ) show a first-degree polynomial for each of them. The variability expressed is $88 \%$ for the maximum

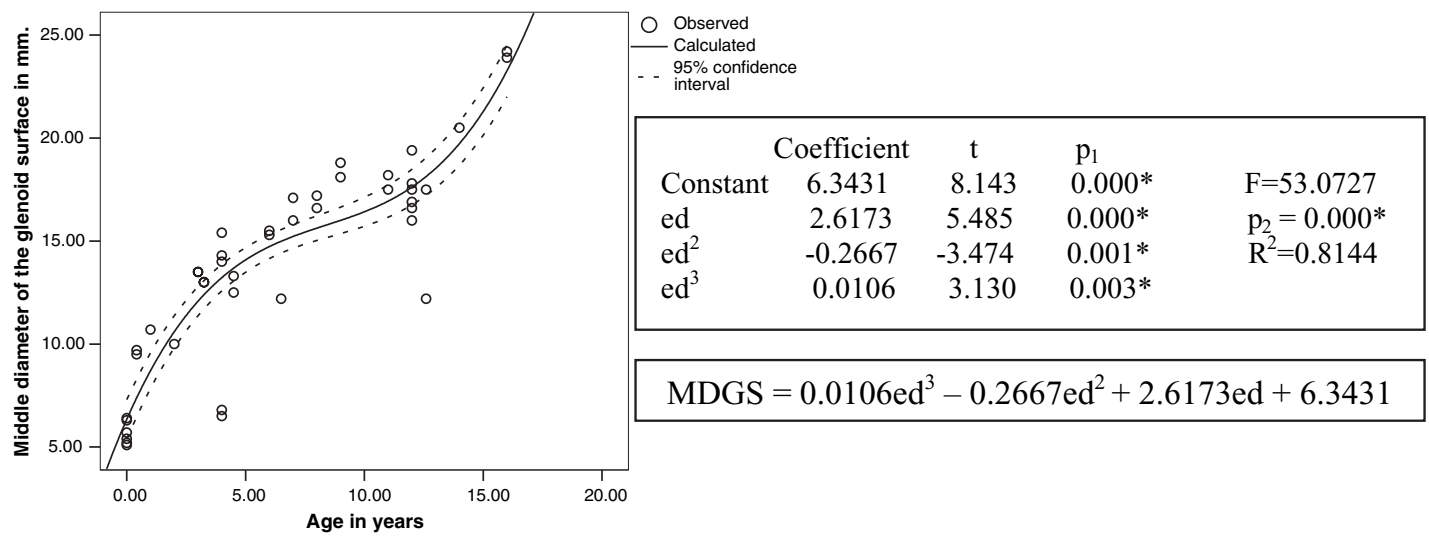

Figure 6. Polynomial regression line with 95\% confidence intervals and equation for middle diameter of the glenoid surface (MDGS). Coefficient=coefficients of the function; ed=age; $t$ and $p_{1}$ the statistical significance of the coefficients; $F$ and $p_{2}$ the significance of the function; and $R^{2}$ the explained variability. 


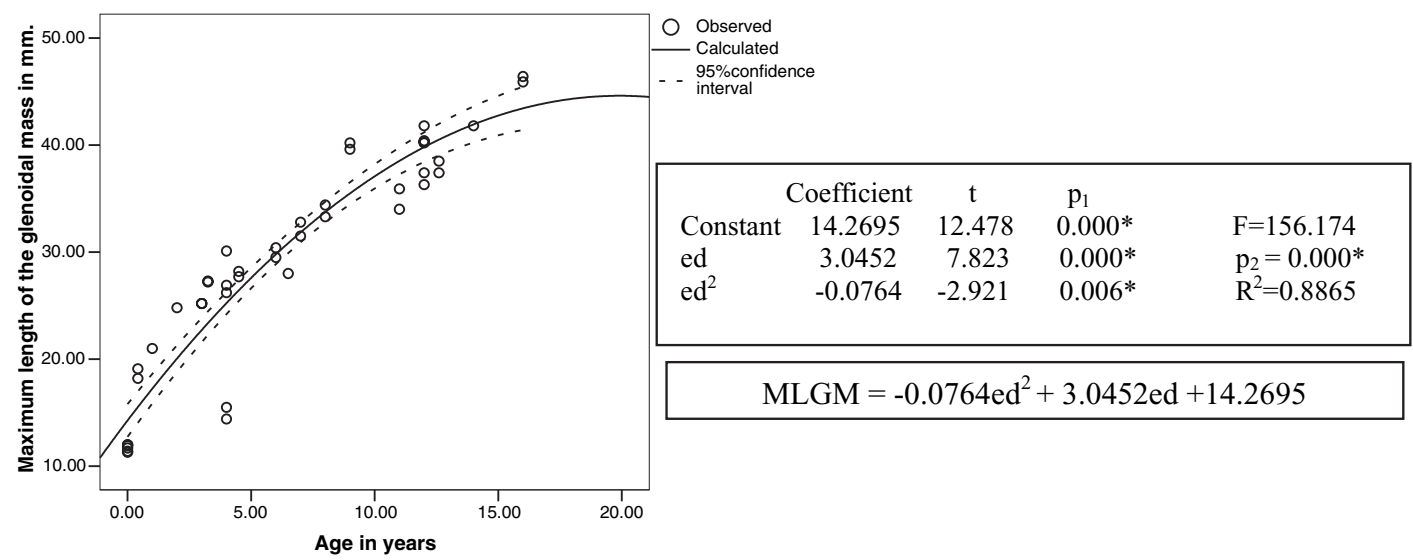

Figure 7. Polynomial regression line with 95\% confidence intervals and equation for maximum length of the glenoidal mass (MLGM). Coefficient = coefficients of the function; ed = age; $t$ and $p_{1}$ the statistical significance of the coefficients; $\mathrm{F}$ and $\mathrm{p}_{2}$ the significance of the function; and $\mathrm{R}^{2}$ the explained variability.

length of the glenoid surface, $78 \%$ for the middle diameter of the glenoid, and $86 \%$ for the maximum length of the glenoidal mass.

\section{Body of the scapula}

Measurements of scapular length, scapular width, infra-scapular and supra-scapular heights, along with scapular index and supra-infra-scapular index, were the variables used to examine growth in the blade or body of the scapula. All of these variables (but not the indices) increase in size until 19 years of age (Table 2). These results suggest that scapular width grows faster than scapular height, and that infra-scapular height grows faster than supra-scapular height during the earlier years. These results are in general agreement with Vallois (1946), who found that in the first years of life supra-scapular height is under-represented in relation to infra-scapular height, and the juvenile scapula is relatively wider than the adult scapula.

In the 17-19 years age group (Table 2), males had larger mean values than females for scapular length, scapular width and infra-scapular height, whereas females were larger than males for supra-scapular height, scapular index and supra-infra-scapular index. However, statistical significance for sexual dimorphism was only evident in scapular length and infra-scapular height (Table 2).

A first-degree polynomial was found to be the most appropriate way to describe growth and

Table 3. Inverse functions for age prediction - coefficient of correlation of the function $\mathrm{R}^{2}$

\begin{tabular}{ll}
\hline & $R^{2}$ \\
\hline Up to 16 years of age & 0.88 \\
Age $=0.63467 \times$ Maximum length of the glenoidal surface -6.545373 & 0.78 \\
Age $=0.855343 \times$ Middle diameter of the glenoidal surface -5.38895 & 0.86 \\
Age $=0.440738 \times$ Maximum length of the glenoidal mass -6.300855 & 0.89 \\
Age $=0.140472 \times$ Scapular length -5.059151 & 0.88 \\
Age $=0.18983 \times$ Infra-scapular height -5.751440 & 0.91 \\
Age $=0.166100 \times$ Spine length -5.160903 & 0.91 \\
Up to 19 years of age & 0.84 \\
Age $=0.262093 \times$ Scapular width -7.489091 & 0.92 \\
Age $=0.528610 \times$ Supra-scapular height -6.811764 & \\
Age $=-0.012320 \times(\text { Acromial width })^{2}+1.068638 \times$ Acromial width -5.069435 & \\
\hline
\end{tabular}




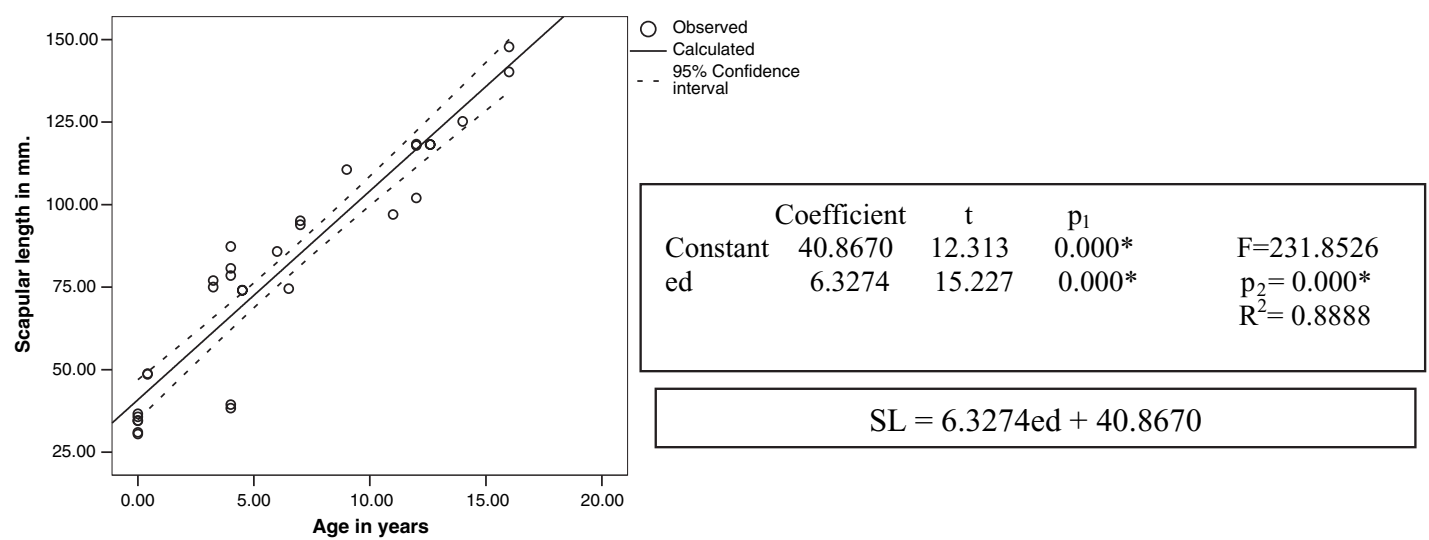

Figure 8. Polynomial regression line with 95\% confidence intervals and equation for scapular length (SL). Coefficient $=$ coefficients of the function; $e d=$ age; $t$ and $p_{1}$ the statistical significance of the coefficients; $F$ and $p_{2}$ the significance of the function; and $\mathrm{R}^{2}$ the explained variability.

development in scapular length (Figure 8), infrascapular height (Figure 9) and supra-scapular height (Figure 10), with $89 \%, 88 \%$ and $84 \%$ of the variability explained respectively. Development of scapular width (Figure 11) was best expressed by a second-degree polynomial regression, with $92 \%$ of variability explained.

Changes in scapular index and supra-infrascapular index were best described by a seconddegree polynomial, with $43 \%$ and $25 \%$ of variability explained respectively. Scapular index displayed decreasing values, indicating that relative increases in scapular width exceeded those in scapular length. Supra-infra-scapular index initially decreased but then increased, indicating that up to 12 years of age, growth in supra-scapular height exceeded that in infrascapular height, but this reverses later. Due to the low expressed variability, its value as predictor of age was not considered.

For the prediction of age at death, scapular length and infra-scapular height proved to be useful discriminators up to 16 years of age, and scapular width and supra-scapular height were of
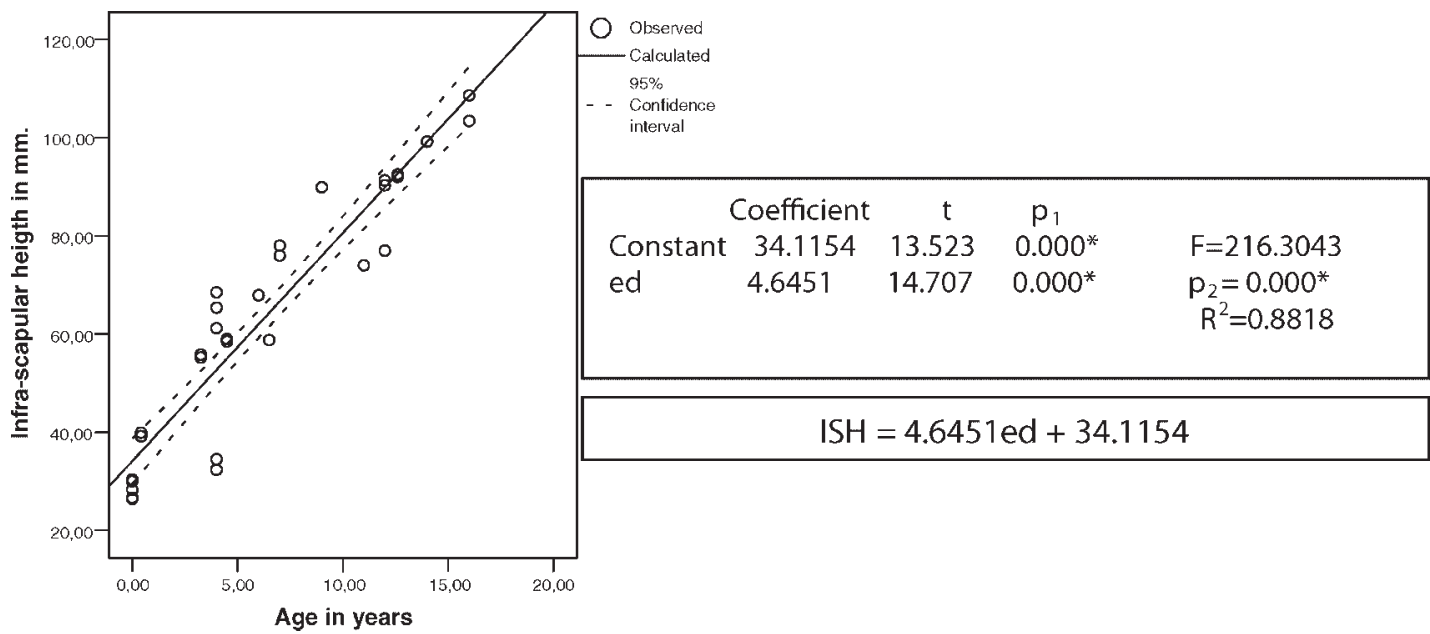

Figure 9. Polynomial regression line with 95\% confidence intervals and equation for infra-scapular height (ISH). Coefficient = coefficients of the function; ed=age; $t$ and $p_{1}$ the statistical significance of the coefficients; $F$ and $p_{2}$ the significance of the function; and $\mathrm{R}^{2}$ the explained variability.

Copyright (C) 2007 John Wiley \& Sons, Ltd.

Int. J. Osteoarchaeol. 17: 451-464 (2007)

DOI: $10.1002 /$ oa 


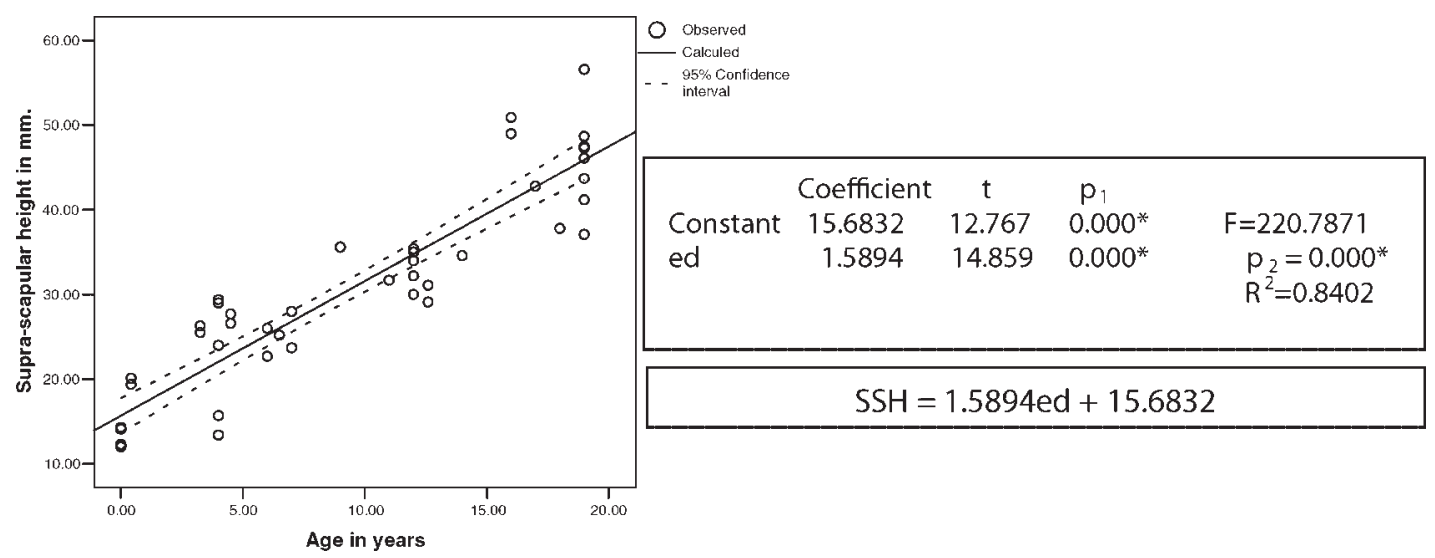

Figure 10. Polynomial regression line with 95\% confidence intervals and equation for supra-Scapular height (SSH). Coefficient = coefficients of the function; ed =age; $t$ and $p_{1}$ the statistical significance of the coefficients; $F$ and $p_{2}$ the significance of the function; and $\mathrm{R}^{2}$ the explained variability.

value up to 19 years of age, prior to the onset of sexual dimorphism. The results of these analyses (Table 3) show a first-degree polynomial inverse relationship with age. The variability expressed is $89 \%$ for scapular length, $88 \%$ for infra-scapular height, $91 \%$ for scapular width and $84 \%$ for supra-scapular height.

\section{Spine and acromion}

Scapular spine length and acromial width increased markedly until 19 years of age (Table 2). Sexual differences were evident in scapular spine length after 16 years of age, where male values were larger than females. Acromial width did not display significant sexual dimorphism (Table 2) and this agrees with the findings of Vallois (1946).

The growth in length of the spine is best expressed by a first-degree polynomial regression (Figure 12) with an explained variability of $91 \%$. In contrast, growth in acromial width is best expressed by a second-degree polynomial (Figure 13) with 90\% explained variability. The form of this curve shows a concavity indicating accelerated growth in this region, which may be

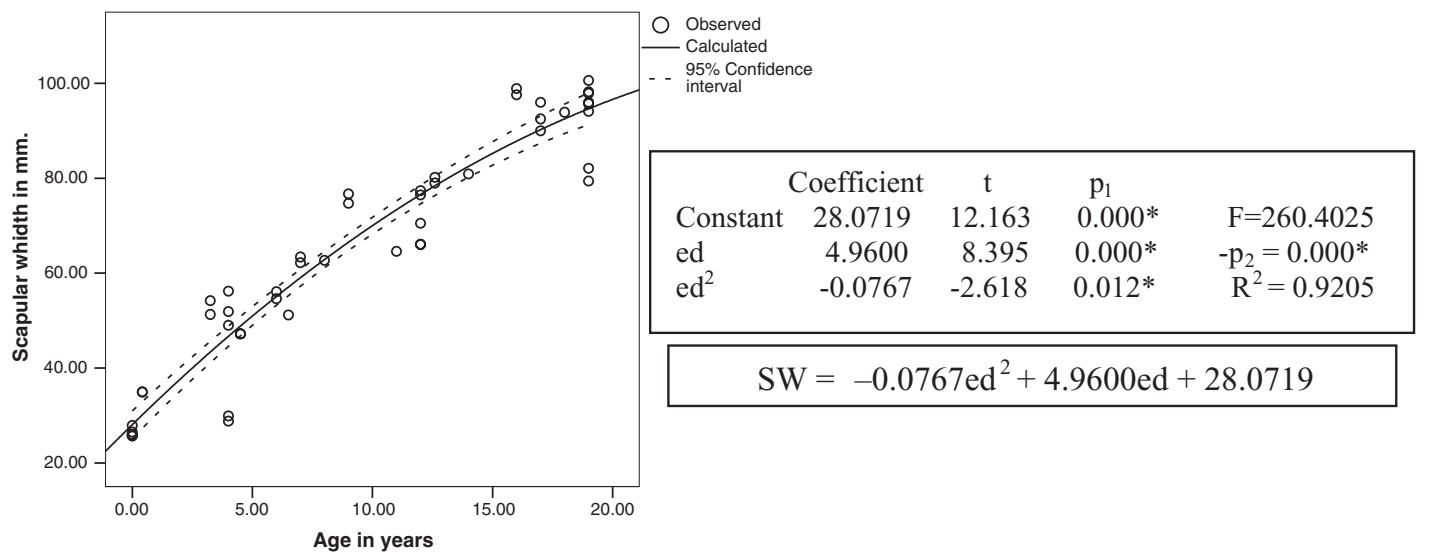

Figure 11. Polynomial regression line with 95\% confidence intervals and equation for scapular width (SW). Coefficient = coefficients of the function; ed =age; $t$ and $p_{1}$ the statistical significance of the coefficients; $F$ and $p_{2}$ the significance of the function; and $R^{2}$ the explained variability. 


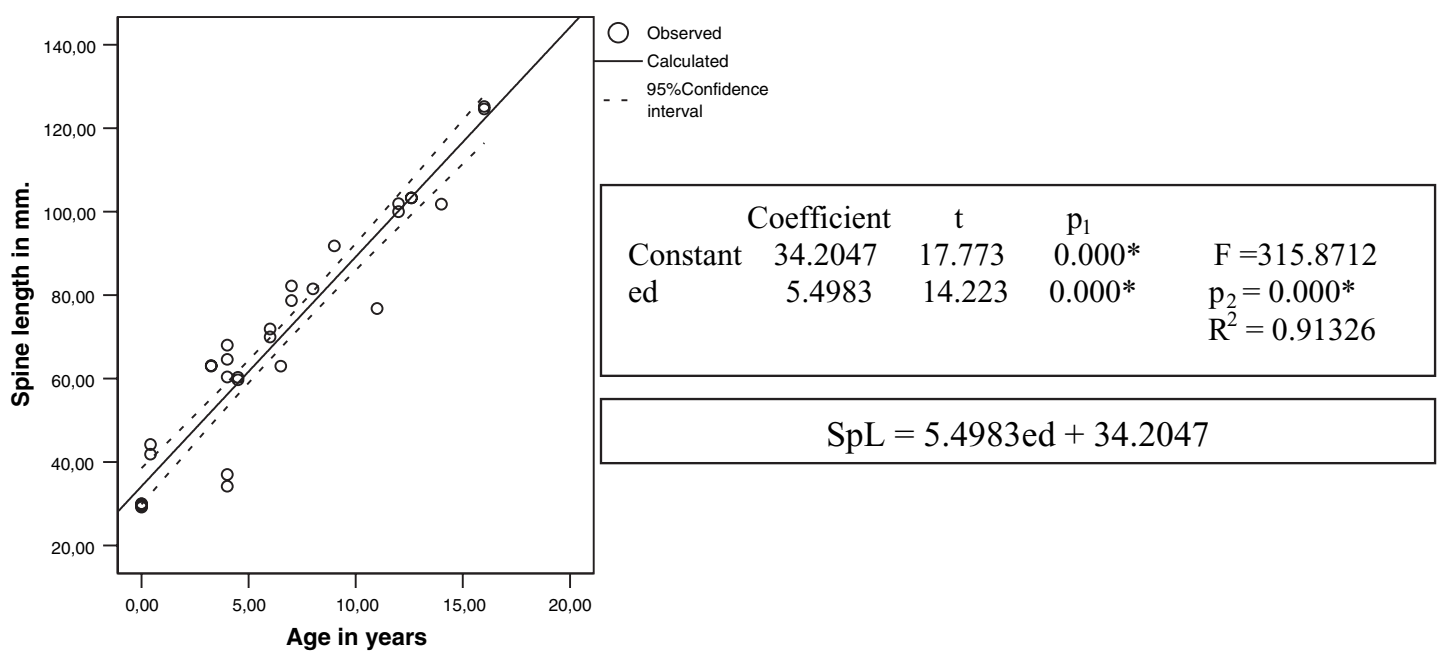

Figure 12. Polynomial regression line with 95\% confidence intervals and equation for spine length (SpL). Coefficient $=$ coefficients of the function; $e d=a g e ; t$ and $p_{1}$ the statistical significance of the coefficients; $F$ and $p_{2}$ the significance of the function; and $\mathrm{R}^{2}$ the explained variability.

explained by the great growth in width of the spinous process and the posterior fusion of the acromial epiphysis, to form the shoulder articulation.

In the prediction of age at death, scapular spine length proved useful up to 16 years of age and the acromial width up to 19 years of age, prior to the development of appreciable sexual dimorphism. The results of the inverse relationship of these variables with age (Table 3) show first- and second-degree polynomials with expressed variability of $91 \%$ and $92 \%$ respectively.

\section{Discussion}

The results of this study show that as the scapula increases in size with age, it proportionally increases more in width than it does in length. However, the growth in length is not a simple

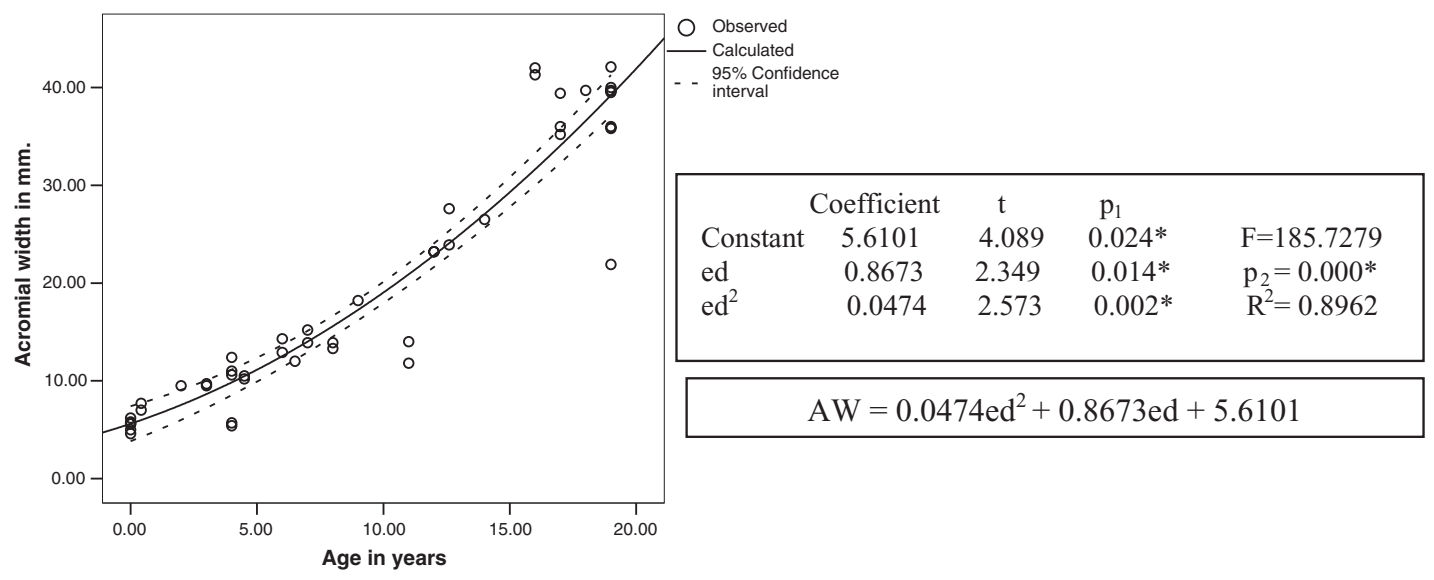

Figure 13. Polynomial regression line with 95\% confidence intervals and equation for acromial width (AW). Coefficient $=$ coefficients of the function; ed $=$ age; $t$ and $p_{1}$ the statistical significance of the coefficients; $F$ and $p_{2}$ significance of the function; and $R^{2}$ explained variability. 
linear function but rather a differential accumulation of parts as the infra-scapular height increases faster than supra-scapular height. In addition, maximum length of the glenoidal surface grows faster than the middle diameter, resulting in the well recognised adult pear shape for this surface.

The development of the absolute variables is essentially linear in form with the exception of the variables which define the glenoidal cavity, scapular and acromial width, which follow third- and second-degree polynomials respectively. Therefore it is possible to observe a growth restraint before adolescent acceleration in maximum and middle diameters of the glenoidal surface. The beginning of the growth spurt for these scapular dimensions is at shortly over 13 years of age (14-15 years of age approximately) and it is observed as a growth acceleration in maximum and middle diameters of the glenoidal surface. It is not possible to determine exactly when this growth spurt commenced, but the approximate age of the growth spurt found for the variables of the glenoidal cavity falls into the standard range of 9.5-14.5 for females and 10.5-17.5 for males in the existing population.

None of the curves show flattening by the age of 19 years, and it is impossible to predict whether flattening would have occurred soon after, but there is perhaps some suggestion that growth can continue in some areas of the scapula after 19 years. These observations agree with the age of complete fusion of the medial epiphysis of the clavicle, and three secondary centres of the scapula: the inferior angle and medial border of the scapula, and the acromion, which fuse around 30,23 and 20 years of age respectively (Black \& Scheuer, 1996; Scheuer \& Black, 2000). In fact, this later growth is not a new finding as it is observed in some parts of the body. The ages of cessation of growth established for the stature were fixed for practical reasons (Tanner, 1962; Roche \& Davila, 1972) and show the end of the most notable growth. Even in the stature there is an increase of $2 \%$, due mainly to body height growth (Tanner, 1962; Büchi, 1950 in Tanner, 1962); thus, certain segments continue to grow, specifically some areas of the vertebral column, innominate and shoulder (Tanner, 1962, 1986; Susanne, 1979; Grasser et al., 1991; Tague, 1994; Rissech et al., 2003; Rissech \& Malgosa, 2005).

From our results, sexual dimorphism is statistically detectable following the anticipated normal adolescent growth spurt, but not before. The pattern of dimorphism exhibited by maximum length of the glenoidal surface, scapular length and supra-scapular height seems to arise due to an earlier cessation of feminine growth (see Table 2). This fact is to be expected since sexual dimorphism in longitudinal variables is caused by the cessation of female growth characteristics rather than the spurt itself (Tanner et al., 1976). This growth behaviour was also observed in anterior osteological studies of the innominate (Rissech et al., 2003; Rissech \& Malgosa, 2005). The variables useful for sex determination after 17 years of age are the maximum length and middle diameter of the glenoidal surface, glenoidal mass length, spine length, scapular length and infra-scapular height. For each of these variables, male values significantly exceed female values.

All of the absolute scapular measurements proved valuable in the determination of age at death in the juvenile. The most useful measurements proved to be acromial width, scapular width and supra-scapular height, where sexually dimorphic change was not detectable prior to 19 years of age. Measurements of the maximum and middle diameters of the glenoidal surface, maximum length of the glenoidal mass, spine length, scapular length and infra-scapular height have a more restricted time period of application, being of value until only 16 years of age.

The formulae proposed in this study allow us to obtain expected growth or to attribute age to young human remains with good reliability. The calculated curves fit well to the analysed juvenile data studied here, and correspond with deductions from previous studies. They are the first formulae obtained from scapula to diagnose the osseous age taking into account the fact that they focus on the scapula until adult age. However, further analysis and additional series are required in order to reinforce the results obtained. Meanwhile, forensic work and anthropological studies can take advantage of these results, which enlarge the possibilities for the analysis of age and sex in juvenile remains.

Int. J. Osteoarchaeol. 17: 451-464 (2007)

DOI: $10.1002 /$ oa 


\section{Conclusion}

This cross-sectional study of scapular growth, based on a documented skeletal collection from Western Europe, has yielded formulae to obtain valuable age estimates of the skeleton, and has thus provided an important tool for osteoarchaeological studies and forensic tasks. It has also provided us with information about sub-adult sexual dimorphism. The importance of the formulae is that they are the first obtained from the scapula to diagnose osseous age, taking into account the fact that they are based on a documented osteological collection from birth to adult age. Grant sponsorship: post-doctoral research grant (SFRH/BPD/6075/2001) from Fundação para a Ciência e a Tecnologia Operational Program Science Technology and Innovation (POCTI) to Carme Rissech.

\section{References}

Alduc-Le Bagouse A. 1988. Estimation de l'âge des non-adultes: maturation dentaire et croissance osseuse. Donées comparatives pour deux nécropoles médievales bas-normandes. In Actes des zèmes Journées Anthropologiques. Notes et Monograpbies techniques 24. CNRS Éditions: Paris; 81-103.

Bainbridge D, Tarazaga S. 1956. A study of sex differences in the scapula. Journal of the Royal Anthropological Institute 86: 109-134.

Black S, Scheuer L. 1996. Age changes in the clavicle: from the early neonatal period to skeletal maturity. International Journal of Osteoarchaeology 6: 425-434.

Bocquet-Appel JP, Masset C. 1985. Matters of moment. Journal of Human Evolution 14: 107-111.

Broca P. 1878. Sur les indices de la largeur de l'omoplate chez l'home, les signes et dans la série des mammifers. Bulletins de la Société d'Antropologie de Paris 1: 66-92.

Brothwell DR. 1981. Digging Up Bones: The Excavation, Treatment and Study of Human Skeletal Remains (3rd edn). Cornell University Press: Ithaca, NY.

Coleman WH. 1969. Sex differences in the growth of the human bony pelvis. American Journal of Physical Anthropology 31: 125-152.

Corrêa D. 1915. Impressões arteriaesda fossa infraspinata da omoplata. Anaes Faulistas de Med e Cirugia, Saõ Paulo 5: 87-92.

Crétot M. 1978. L'arcade dentaire bumaine (Morphologie). Julien Prélat: Paris.
Dorsey G. 1897. Observations on the scapula of Northwest Coast Indians. American Naturalist 31 : 736-745.

Dwight T. 1887. The range of variation of the human shoulder-blade. American Naturalist 21: 627-638.

Fazekas IG, Kósa F. 1978. Forensic Fetal Osteology. Akadémiai Kiadó: Budapest.

Genoves S. 1959. Diferencias sexuales en el bueso coxal. Universidad Nacional Autónoma de México, Publicaciones del Instituto de Historia: Mexico.

Grasser T, Kneip A, Ziegler P, Largo R, Molinari L, Prader A. 1991. The dynamics of growth of width in distance, velocity and acceleration. Annals of Human Biology 18: 449-461.

Graves WW. 1921. The types of scapula: a comparative study of some correlated characters in human scapulae. American Journal of Physical Antbropology 4: 111-128.

Graves WW. 1922. Observations on age changes in the scapula. American Journal of Physical Antbropology 5: 21-33.

Gray DJ. 1942. Variations in human scapulae. American Journal of Pbysical Antbropology 29: 57-72.

Hanihara K. 1959. Sex diagnosis of Japanese skulls and scapulae by means of discriminant functions. Journal of the Antbropological Society of Nippon 67: 21-27.

Hrdlicka A. 1942a. The adult scapula: additional observations and measurements. American Journal of Physical Antbropology 29: 363-415.

Hrdlicka A. 1942b. The juvenile scapula: further observations. American Journal of Pbysical Antbropology 29: 287-310.

Iordanidis P. 1961. Détermination du sexe par les os du sequelette. Annales de Médecine Légale 41: 280-291.

Kahana T, Birkby WH, Goldin L, Hiss J. 2003. Estimation of age in adolescents. The basilar synchondrosis. Journal of Forensic Science 48:1-5.

Khoo FY, Kuo CL. 1948. An unusual anomaly of the inferior portion of the scapula. Journal of Bone and Joint Surgery 30: 1010-1011.

Krogman WM, Iscan MY. 1986. The Human Skeleton in Forensic Medicine. CC Thomas: Springfield, IL.

Major T. 2000. L'os coxal non-adulte: approche métbodologique de la croissance et de la diagnose sexuelle. Application aux enfants du paléolithique moyen. $\mathrm{PhD}$ dissertation, Université Bordeaux I, France.

McKern TW, Stewart TD. 1957. Skeletal age changes in young American males, analysed from the standpoint of age identification. Headquarters Quartermaster Research and Development Command, Technical Report EP45. Natick, MA.

Miles AEW, Bulman JS. 1995. Growth curves of immature bones from a Scottish island population 
of sixteenth to mid-nineteenth century: shoulder girdle, ilium, pubis and ischium. International Journal of Osteoarchaeology 5: 15-27.

Olivier G. 1960. Practique anthropologique. Vigot Frères, Éditeurs: Paris.

Olivier G, Pineau H. 1957. Biométrie du scapulum, asymétrie, corrélations et différences sexueles. Archives d'Anatomie de Paris 33: 67-68.

Pospísil M. 1965. Manual de prácticas de Antropología Física. Editorial nacional de Cuba. Editora del consejo nacional de Universidades: Havana (Cuba).

Rissech C. 2003. Determinación de la edad de restos esqueléticos infantiles y adolescentes. In Paleopatología, la enfermedad no escrita, Isidro A, Malgosa A (eds). Masson SA: Barcelona; 47-56.

Rissech C, Malgosa A. 1997. Sex prediction by discriminant function with central portion measures of innominate bones. Homo 48: 22-32.

Rissech C, Malgosa A. 2005. Ilium growth study: applicability in sex and age diagnosis. Forensic Science International 147: 165-174.

Rissech C, Garcia MM, Malgosa A. 2003. Sex and age diagnosis by ischium morphometric analysis. Forensic Science International 135: 188-196.

Roche AF, Davila GH. 1972. Late adolescent growth in stature. Pediatrics 50: 874-880.

Saunders S, Hoppa R, Southern R. 1993. Diaphyseal growth in a nineteenth century skeletal sample of sub adults from St Thomas' Church, Belleville, Ontario. International Journal of Osteoarchaeology 3: 265-281.

Scheuer JL, Black SM. 2000. Developmental Juvenile Osteology. Academic Press: London.

Scheuer JL, Black SM. 2004. The Juvenile Skeleton. Elsevier: London.

Schulter-Ellis FP. 1980. Evidence of handedness on documented skeletons. Journal of Forensic Sciences 25: 624-630.

Schutkowski H. 1987. Sex determination of fetal and neonate skeletons by means of discriminant analysis. International Journal of Antbropology 2: 347352.

Schutkowski H. 1993. Sex determination of infant and juvenile skeletons: I Morphognostic features. American Journal of Physical Antbropology 90: 199-205.

Shulin P, Fangwu Z. 1983. Estimation of stature from skull, clavicle, scapula and os coxa of male adult of Southern China. Acta Anthropologica Sinica 2: 253259.

Strádalová V. 1978. Statistické metody bodnocení rustu deti, Kand. Pace, katedra antropologie Prf UK: Prague.

Susanne C. 1979. Ageing, continuous changes of adulthood. In Human Pbysical Growth and Maturation: Methodologies and Factors, Johnston FE, Roche AF, Susanne C (eds). Plenum Press: New York; 203-218.

Tague RG. 1994. Maternal mortality or prolonged growth: age at death and pelvic size in three prehistoric Amerindian populations. American Journal of Pbysical Antbropology 95: 27-40.

Tanner JM. 1962. Growth at Adolescence (2nd edn). Blackwell Scientific Publications: Oxford.

Tanner JM. 1986. El bombre antes del hombre. Fondo de cultura económica: México.

Tanner JM, Whitehouse RH, Marubini E, Resele LF. 1976. The adolescent growth spurt of boys and girls of the Harpenden Growth Study. Annals of Human Biology 3: 109-126.

Ubelaker DH. 1989. Human Skeletal Remains. Excavation, Analysis, Interpretation. Manuals on Archaeology 2 (2nd edn). Washington Taraxacum: Washington, DC.

Vallois HV. 1946. L'omoplate humaine. Bulletin de la Société d'Anthropologie de Paris 7: 16-99.

Weaver DS. 1979. Application of the likelihood ratio test to age estimation using the infant and child temporal bone. American Journal of Pbysical Antbropology 50: 263-270.

Wolffson DM. 1950. Scapula shape and muscle function with special reference to vertebral border. American Journal of Physical Antbropology 8: 331-342. 